\title{
Analysis of Facial Paralysis Disease using Image Processing Technique
}

\author{
K. Anguraj \\ Assistant Professor, ECE, \\ Sona College of Technology, \\ Salem, Tamilnadu, India
}

\author{
S.Padma \\ Professor, EEE \\ Sona College of Technology \\ Salem, Tamilnadu, India
}

\begin{abstract}
Facial paralysis is a disease that occurs due to the disorder of neuromuscular system. It may affect on one or both sides of the face. Facial paralysis will lead to significant physical and functional hurt to patients. To diagnose the disease, degree of facial paralysis has to be evaluated. The proposed method is to evaluate the degree of facial paralysis by using IECM algorithm. The initial stages of diseases are detected by analyzing the various facial expressions. The proposed method includes preprocessing of images and estimation of level of diseases. The proposed algorithm measures the distance between the eye brows to infra orbital. It also measures the distance between the edges of mouth and lateral canthus. Diseases levels are identified as Normal, mild and severe by using the estimated parameters.
\end{abstract}

\section{General Terms}

Facial paralysis, left and right face, IECM Algorithm.

\section{Keywords}

Infraorbital, Eyebrow, Lateral Canthus and Mouth edge.

\section{INTRODUCTION}

The facial motor system is responsible for various facial expressions like conveying conversational signal and intimating human information[6]. Any dysfunction in the facial motor system will results in the deficits of facial expressions. Injury of seventh carnial nerve will lead to facial paralysis. This diseases results in the deformity of face and intricacies in the daily living such as taking food, drinking and communicating with others[3]. Due to facial paralysis the corners of the mouth and eyebrows are drooped. Voice timbres are also affected. Toronto facial grading system(TFGS), facial nerve function index(FNFI), Linear measurement index(LMI), House-Brackmann(H-B) system and Nottingham system are the methods used to evaluate the degree of facial paralysis[14]. Figure 1 shows the block diagram of proposed system.

\section{PRE-PROCESSING}

Input image is subjected to preprocessing stage. Preprocessing of image includes filtering, morphological process and image dilations. Eyebrows, infraorbital, mouth edges and lateral canthus are extracted in stages.

\subsection{Median filter}

The filter is used to reduce the unwanted noises in the image. The median filter is preferred over the other filters. Optimal results are obtained after applying the median filter to the image. The median filters are used to provide the efficient filter for facial paralysis. It estimates the information from one pixel to another neighborhood pixel. Even the smaller noise information's are filtered by using this median filter. It uniformly filters the information for low, medium and large signals.

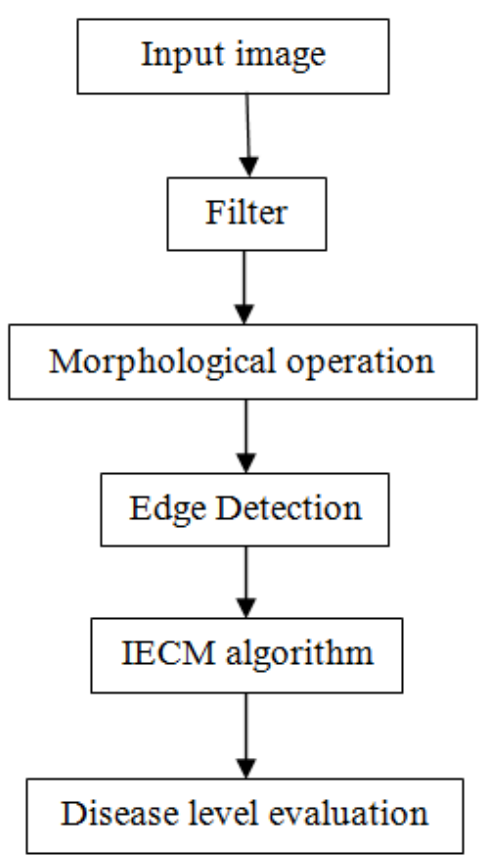

Fig 1: Block diagram

\subsection{Morphological Dilation}

Morphological processing is constructed with the operations on sets of pixels. Using dilation, the original image is converted into binary image. Dilation uses structuring element for image conversion process.

\subsection{Edge detection}

Edges often occur at points where there is a large variation in the luminance values in an image, and consequently they often indicate the edges, or occluding boundaries of the image. There are various types of edge detectors are available like sobel, robert, prewitt, log. In the proposed method, the canny edge detection technique gives out efficient edges of eyebrow and mouth edges as compared with other techniques.[9] In Canny edge detection before trying to locate a mouth edge and eyebrow, unwanted noise present in the image should be removed[2]. For filtering the noise the, Gaussian filter with suitable iteration was selected by 
experimentally and noise was eliminated. At the same time by using sobel edge detection is used to find the edges of lateral canthus and infraorbital.

\subsection{IECM algorithm}

IECM algorithm is used to place the landmark points on the centre of eyebrows, centre of infraorbital, mouth edges and lateral canthus for various facial expressions. For normal person, the landmark points on the both sides of face should be horizontally straight, but for the paralyzed affected person it will not be straight. This algorithm calculates the distance between the various landmark points as follows

\section{Step 1:}

Distance between centre of eyebrows (CE) and centre of infraorbital (CI) is measured while eyebrows are raised.

Step 2:

Distance between centre of eye brows (CE) and centre of infraorbital (CI) is measured while eyes are closed tightly.

Step 3:

Distance between the edges of the mouth (ME) and lateral canthus (EC) while opening the mouth.

\section{Step4:}

During the facial expression like screwing of nose, distances between edges of the mouth (ME) and external canthus (EC) are calculated.

Based on the result the diseases level is evaluated. Figure 2 shows the paralysis affected image.

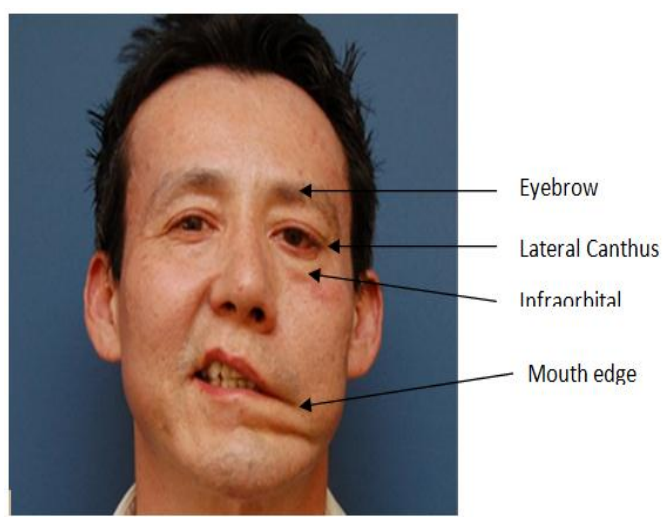

Fig 2: Paralysis Affected Image

\section{EXPERIMENTAL RESULTS}

Images are selected based on the human under normal and different expressions. Figure 3, 4, 5 \& 6 shows the various facial expressions like eye brow raised, eyes closed tightly, Mouth opened, Screwing Nose. From this expressions diseases affected level can be calculated.

The table 1, 2, 3 and 5 show the experimental results of the proposed method. The table 4 shows the diseases level of person-1. In the result, the person 1 is affected with degree of disease less than 1 and disease level is classified as mild. Finally the graphical screen displays the person-1 diseases level as mild, shown in the Figure 4. The table- 6 compares the exiting facial parameter results with the proposed technique and the corresponding graphical plot is shown in Fig. 8
Table 1. Calculated distance Eyebrow raised

\begin{tabular}{|c|c|c|c|c|}
\hline \multirow{2}{*}{ Person } & \multicolumn{4}{|c|}{ Eyebrow raised } \\
\cline { 2 - 5 } & \multicolumn{2}{|c|}{ Left } & \multicolumn{2}{c|}{ Right } \\
\cline { 2 - 5 } CE & CI & CE & CI \\
\hline Person- 1 & $(16,13)$ & $(18,52)$ & $(71,10)$ & $(72,44)$ \\
\hline Person-2 & $(14,9)$ & $(18,5)$ & $(80,2)$ & $(80,43)$ \\
\hline Person-3 & $(19,13)$ & $(21,50)$ & $(78,10)$ & $(76,47)$ \\
\hline
\end{tabular}

Table 2. Calculated distance Eyes closed tightly

\begin{tabular}{|c|c|c|c|c|}
\hline \multirow{2}{*}{ Person } & \multicolumn{3}{|c|}{ Eyes closed tightly } \\
\cline { 2 - 5 } & \multicolumn{2}{|c|}{ Left } & \multicolumn{2}{c|}{ Left } \\
\cline { 2 - 5 } & CE & CE & CE & CE \\
\hline Person- 1 & $(20,12)$ & $(20,12)$ & $(20,12)$ & $(20,12)$ \\
\hline Person-2 & $(15,8)$ & $(15,8)$ & $(15,8)$ & $(15,8)$ \\
\hline Person-3 & $(23,10)$ & $(23,10)$ & $(23,10)$ & $(23,10)$ \\
\hline
\end{tabular}

Table 3. Calculated distance mouth opened

\begin{tabular}{|c|c|c|c|c|}
\hline \multirow{2}{*}{ Person } & \multicolumn{4}{|c|}{ Mouth opened } \\
\cline { 2 - 5 } & \multicolumn{2}{|c|}{ Left } & \multicolumn{2}{c|}{ Left } \\
\cline { 2 - 5 } & ME & ME & ME & ME \\
\hline \multirow{2}{*}{ Person- 1 } & $(35,87)$ & $(35,87)$ & $(35,87)$ & $(35,87)$ \\
\hline Person-2 & $(34,84)$ & $(34,84)$ & $(34,84)$ & $(34,84)$ \\
\hline Person-3 & $(38,80)$ & $(38,80)$ & $(38,80)$ & $(38,80)$ \\
\hline
\end{tabular}

Table 4. Disease level of patient-

\begin{tabular}{|c|c|c|}
\hline Expressions & Left & Right \\
\hline Eyebrow raised & $(2,37)$ & $(2,37)$ \\
\hline Eyes closely tightly & $(2,40)$ & $(1,37)$ \\
\hline Mouth opened & $(27,69)$ & $(18,58)$ \\
\hline Screwing nose & $(22,52)$ & $(22,46)$ \\
\hline Total & $(53,198)$ & $(43,178)$ \\
\hline Current Threshold & 0.898 & 0.811 \\
\hline
\end{tabular}

Table 5. Calculated distance Screwing nose

\begin{tabular}{|c|c|c|c|c|}
\hline \multirow{2}{*}{ Person } & \multicolumn{4}{|c|}{ Screwing nose } \\
\cline { 2 - 5 } & \multicolumn{2}{|c|}{ Left } & \multicolumn{2}{c|}{ Left } \\
\cline { 2 - 5 } & ME & ME & ME & ME \\
\hline $\begin{array}{c}\text { Person- } \\
1\end{array}$ & $(34,61)$ & $(34,61)$ & $(34,61)$ & $(34,61)$ \\
\hline Person-2 & $(31,89)$ & $(31,89)$ & $(31,89)$ & $(31,89)$ \\
\hline Person-3 & $(33,81)$ & $(33,81)$ & $(33,81)$ & $(33,81)$ \\
\hline
\end{tabular}




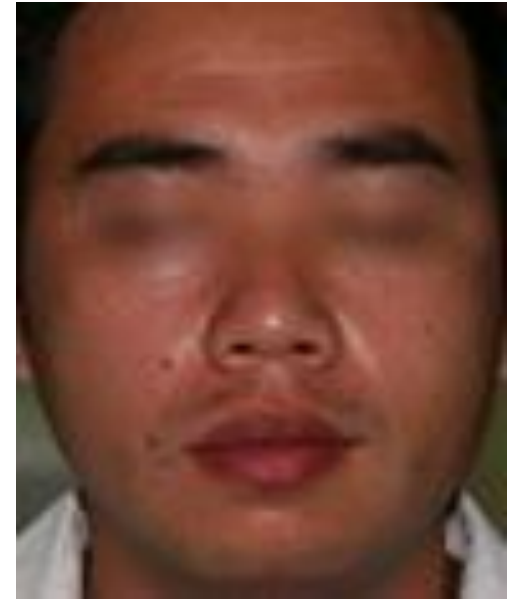

Fig 4: Eyes closed tightly

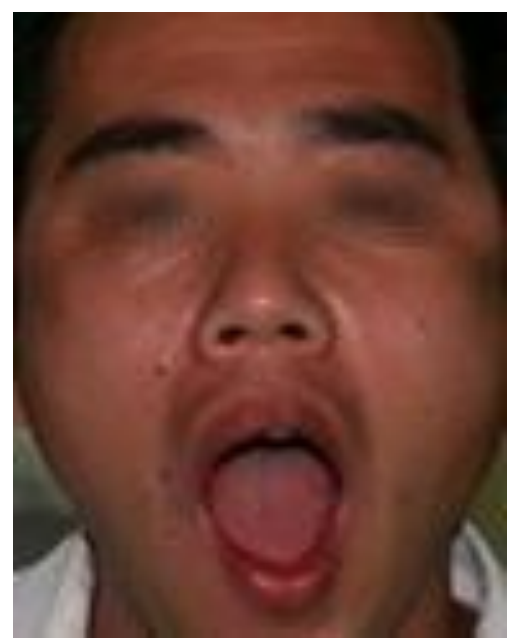

Fig 5: Mouth opened

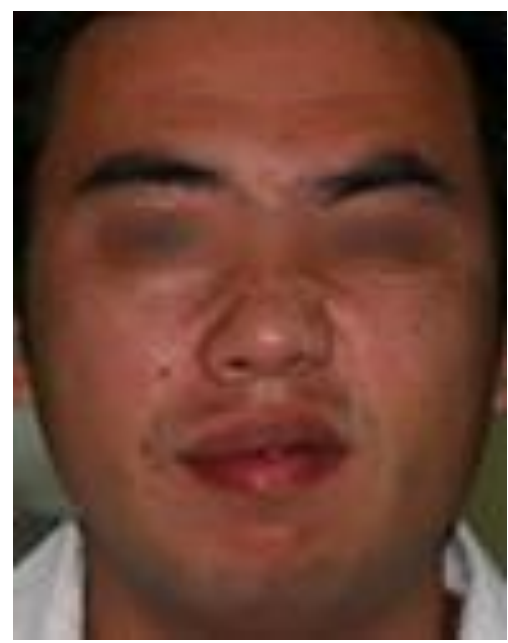

Fig 6: Screwing Nose

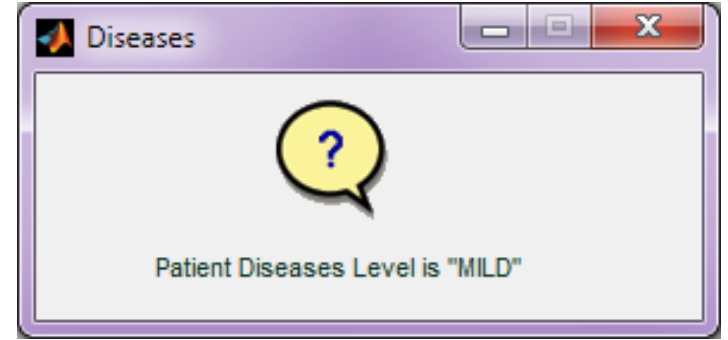

Fig 7: Patient's Diseases Level

Table 6. Comparison of existing $\&$ proposed technique

\begin{tabular}{|c|c|c|}
\hline DESCRIPTION & $\begin{array}{c}\text { EXISTING } \\
\text { METHOD }\end{array}$ & $\begin{array}{c}\text { PROPOSED } \\
\text { METHOD }\end{array}$ \\
\hline Eye brow rise & $86.1 \%$ & $86.5 \%$ \\
\hline $\begin{array}{c}\text { Eye brow closed } \\
\text { tightly }\end{array}$ & $73.9 \%$ & $78 \%$ \\
\hline Screwing nose & $83.6 \%$ & $84 \%$ \\
\hline Mouth opened & $92.1 \%$ & $93 \%$ \\
\hline Average Level & 83.9 & $85.38 \%$ \\
\hline
\end{tabular}

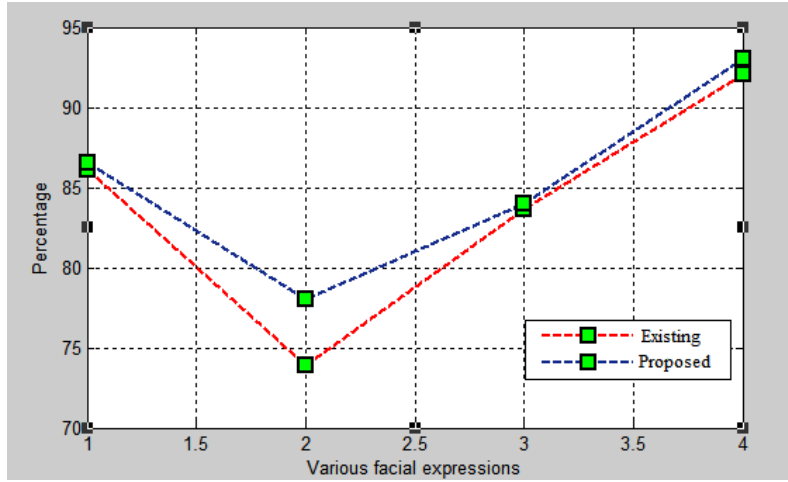

Fig 8: Comparison Plot

\section{CONCLUSION}

The paralysis makes a critical position to the human. The mouth was a first affected human part in the face and similarly other parts face like Eyebrow, Infraorbital and Screwing nose. By using the mouth edge position and Lateral Canthus, the disease level was predicted. The image data base was prepared by using human at normal condition and the same human at different facial expressions. The proposed method exactly works for the collected images. The proposed method used the IECM algorithm, which accurately finds disease level in the face. The proposed technique uses the 4 different facial expressions. In future more no. of expressions are added in the proposed technique, to achieve more accuracy.

\section{REFERENCES}

[1] Chan EH, Tan HM and Tan TY, May 2005, "Facial palsy from temporal bone lesions", Annals Academy of Medicine Singapore, Vol. 34, No. 4, pp. 322-329. 
[2] Anguraj.K, Kandiban.R and Jayakumar.K.S, "Facial Paralysis Diseases Level Detection using CEMAlgorithm for Clinical Applications", European Journal of Scientific Research, Vol. 77, No. 4, pp. 543-548.

[3] Elisabet Cederwall, Monika Fagevik Olsen, Per Hannerand Ingemar Fogdestam, 2006,"Evaluation of a physiotherapeutic treatment intervention in "Bell's" facial palsy", Physiotherapy Theory and Practice, Vol. 22, No. 1, pp. 43-52.

[4] Balliet, Shinn and Bach-Y-Rita, 1982, "Facial paralysis rehabilitation: retraining selective muscle control", International Rehabilitation Medicine, Vol. 4, No. 2, pp. $67-74$

[5] William W. Qiu, Shengguang S. Yin, Fred J. Stucker and Denis K. Hoasjoe, 1997, "Neurophysiological evaluation of acute facial paralysis in children", International Journal of Pediatric Otorhinolaryngology, Vol. 39, pp. 223-236

[6] Jessie $M$ VanSwearingen and Jennifer $S$ Brach, December 1996, "The Facial Disability Index: Reliability and Validity of a Disability Assessment Instrument for Disorders of the Facial Neuromuscular System, Physical Therapy, Vol. 76, No. 12, pp. 1288-1298.

[7] Jessie VanSwearingen, 2008, "Facial Rehabilitation: A Neuromuscular Reeducation, Patient-Centered Approach", 2001, Facial Plastic Surgery, Vol. 24, No. 2, pp. 250-259.

[8] Josephine Clark Weeden, Carroll-Ann Trotman and Julian J. Faraway, "Three Dimensional Analysis of Facial Movement in Normal Adults: Influence of Sex and Facial Shape", Angle Orthodontists, Vol. 71, No. 2, pp. 132-140.

[9] Thiyaneswaran B, Kandiban R, Jayakumar K.S. 2012. Localization of iris region using MLRP algorithm intended for biometric applications, European journal of scientific research(EJSR), Vol. 74, Issue 1, pp.126-133.
[10] Mervi Kanerva, 2008, "Peripheral facial palsy, grading, etiology, and Melkersson-Rosenthal syndrome", Department of Otorhinolaryng, University of Helsinki Finland.

[11] Peter Eisert, 2003, "MPEG-4 Facial animation in video analysis and synthesis", International Journal of Imaging Systems and Technology, Vol. 20, pp. 100-110.

[12] Hontanilla and Auba, January 2008, "Automic threedimensional quantitative analysis for evaluation of facial movement", Journal of Plastic, Reconstructive \& Aesthetic Surgery, Vol. 61, No. 1, pp. 18-30.

[13] Thiyaneswaran.B and Padma. S, July 2012, "Iris recognition using left and right iris feature of the human eye for Bio-metric security system", International Journal of Computer Applications, Vol. 50, No. 12, pp 37-41.

[14] Junyu Dong, Lijing Ma, Qingqiang Li, Shengke Wang, Li-an Liu, Yang Lin and Muwei Jian, 2008, "An approach for quantitative Evaluation of the degree of Facial Paralysis based on salient point detection", International Symposium on Intelligent Information Technology Application Workshop, pp 483-486.

[15] Y.Liu, K. L. Schmidt, J. F. Cohn and S. Mitra, 2003, "Facial asymmetry quantification for expression invariant human identification", Computer Vision and Image Understanding, Vol. 91, no.1-2, pp 138-159.

[16] M. H. Yang, 2004, "Recent advances in Face Detection", 17th International Conference on Pattern Recognition, Cambridge, UK.

[17] Yaoyao Cui, Mingxi Wan and Junbo Li, 1998, "A new quantitative assessment method of facial paralysis based on motion estimation", Annual International Conference of the IEEE Engineering in Medicine and Biology Biology Society, Vol. 20, No.3, pp 1412-1413. 